\title{
Hypertension in Autosomal Dominant Polycystic Kidney Disease
}

\author{
Arlene B. Chapman, MD ${ }^{1}$, Konrad Stepniakowski, MD, PhD², and Frederic Rahbari-Oskoui, \\ MD1 \\ ${ }^{1}$ Emory University School of Medicine, Atlanta, GA \\ 2 Mid-South Nephrology Consultants, Memphis, TN
}

\begin{abstract}
Hypertension is common and occurs in a majority of autosomal dominant polycystic kidney disease (ADPKD) patients prior to loss of kidney function. Hypertension relates to progressive kidney enlargement, and is a significant independent risk factor for progression to end stage renal disease. The pathogenesis of hypertension in ADPKD is complex and dependent on many factors that influence each other.
\end{abstract}

$P k d 1$ and $P k d 2$ expression levels are highest in the major vessels and are present in the cilia of endothelial cells and in vascular smooth muscle cells. Decreased or absent polycystin 1 or 2 expression is associated with abnormal vascular structure and function. Pkd1/Pkd2 deficiency results in reduced nitric oxide (NO) levels, altered endothelial response to shear stress with attenuation in vascular relaxation.

10-20\% of ADPKD children demonstrate hypertension and the majority of adults are hypertensive before any loss of kidney function. Cardiac abnormalities such as left ventricular hypertrophy and carotid intimal wall thickening are present prior to the development of hypertension in ADPKD.

Activation of the renin-angiotensin-aldosterone system occurs in ADPKD due to decreased NO production as well as bilateral cyst expansion and intra-renal ischemia. With increasing cyst size, further activation of the RAAS occurs, blood pressure increases and a vicious cycle ensues with enhanced cyst growth and hypertension ultimately leading to ESRD.

Inhibition of the angiotensin aldosterone system is possible with angiotensin converting enzyme inhibitors and angiotensin receptor blockers. However, interventional studies have not yet demonstrated benefit in slowing progression to renal failure in ADPKD. Currently, large multicenter studies are being performed to determine the beneficial effects of RAAS inhibition both early and late in ADPKD.

\section{Introduction}

Autosomal dominant polycystic kidney disease (ADPKD) is a systemic disorder and the most common hereditary kidney disease, occurring in approximately 1:1,000 individuals (1). Renal manifestations of ADPKD are characterized by gradual cystic expansion resulting in enlarged kidneys ultimately progressing to renal failure in the $5^{\text {th }}$ decade of life (1-3). Extra-renal manifestations of ADPKD include hypertension, liver cystic disease, intracranial aneurysms,

Corresponding Author: Arlene Chapman, MD, 1364 Clifton Rd, Suite GG23, Atlanta, GA 30322, Tel: 404-712-1993, Fax: 404-727-5563, Arlene.chapman@emoryhealthcare.org.

Publisher's Disclaimer: This is a PDF file of an unedited manuscript that has been accepted for publication. As a service to our customers we are providing this early version of the manuscript. The manuscript will undergo copyediting, typesetting, and review of the resulting proof before it is published in its final citable form. Please note that during the production process errors may be discovered which could affect the content, and all legal disclaimers that apply to the journal pertain. 
inguinal and ventral hernias, diverticular disease, arachnoid, thyroid, pancreatic and splenic cysts, and abnormalities in the seminal vesicle cysts.

The commonest cause of death in ADPKD patients in the post-dialysis era is cardiovascular $(4,5)$. Autopsy studies of ADPKD individuals dying due to cardiovascular causes show significant and severe cardiac hypertrophy ( $>92 \%)$ as well as accompanying coronary artery disease $(85 \%)$. Although cerebrovascular deaths in ADPKD are relatively uncommon, hypertension appears to play an important role in both intracranial and subarachnoid hemorrhage (6). Hypertension is common and occurs in the majority of adults prior to loss of kidney function (7-9), unlike other renal diseases. Hypertension relates to progressive kidney enlargement, and is a significant independent risk factor for progression to end stage renal disease $(10,11)$ with a diagnosis of hypertension prior to age 35 identifying the subset of ADPKD patients most likely to progress to renal failure (11).

The pathogenesis of hypertension in ADPKD is complex and depends on many inter-related factors that influence each other. Whether hypertension is due to abnormal endothelial or vascular function related to decreased polycystin expression or secondary to renal cystic expansion and intra-renal ischemia is unclear. Given that cardiovascular causes account for the majority of deaths in ADPKD, and that hypertension directly relates to cardiovascular morbidity and mortality, understanding and treating hypertension in ADPKD is worthy of careful attention.

\section{The Polycystins Are Required for Normal Vascular Development}

Polycystin 1 and 2 are the protein products of the PKD1 and PKD2 genes. Pkdl expression data from heterozygous and homozygous knockout mouse models, as well as isolated endothelial and vascular smooth muscle cells, demonstrate defects in vascular function. Homozygous mice with a targeted mutation in Pkd1 die in utero at mid-gestation due to major developmental cardiovascular defects including double outflow right ventricles, disorganized myocardium, and abnormal atrio-ventricular septation as well as subcutaneous edema and massive peripheral and pericardial hemorrhage due to focal vascular leaks and rupture of blood vessels (12). During embryogenesis, Pkd1 expression is detected first in the neural crest and aorta and later in all major vessels. Pkd1 expression is present in all structures of the heart during embryonic development with the highest expression in the outflow tracts, endocardial cushions and valve leaflets with lower expression in the myocardium. Cardiac manifestations differ across different Pkd1 mutant mice strains (13-17), suggesting that the site or type of mutation in human PKD1 may play an important role in cardiac development.

Similar to humans with ADPKD, pathologic phenotypes are indistinguishable for Pkd1 and Pkd2 targeted mutant mice, however Pkd1 and Pkd2 expression patterns (polycystin 1 and 2) differ (13). Pkd2 plays a central role in nodal cilia (14) which regulates normal axis determination including the heart. Homozygous mutant embryos show right pulmonary isomerism, randomization of embryonic turning, heart looping, abdominal situs, defects in cardiac septation and focal hemorrhage and total body edema (13,18 new reference: Pennekamp P, Karcher C, Fischer A, Schwickert A, Skryabin B, Horst J, Blum M, Dworniczak $B$. The ion channel polycystin-2 is required for left right axis determination in mice. Curr Biol 4:12(11):938-43,2002.). Pkd1 expression appears to be more developmentally regulated than $\mathrm{Pkd} 2$, where more constant expression levels are found during embryonic development and throughout the post natal period.

Expression levels of Pkd1 are high throughout the heart in adult mice (12). Expression is highest in the aortic outflow tract and atrial appendages and in endothelial and vascular smooth muscle cells of the major vessels including the aorta, and intracranial arteries. Notably, Pkd1 is expressed in adult afferent arterioles (15) and hypomorphic Pkd1 allele mice, a murine model 
of ADPKD that survives embryonic development and demonstrates a vascular phenotype show systemic dissecting aneurysms (19). In Pkd2+/- mice intracranial vascular abnormalities are observed when hypertension is induced.

\section{Abnormal Endothelial and Vascular Smooth Muscle Cell Function in Murine and Human ADPKD}

Both Pkd 1 and 2 are expressed in endothelial and vascular smooth muscle cells of all major vessels. Impaired endothelial dependent relaxation has been demonstrated from cells of aortas from Pkd1 knockout mice due to a defect in nitric oxide (NO) release from the endothelium correlating with a decrease in $\mathrm{Ca}^{2+}$ dependent endothelial NO syntheses activity (19). Interactions between polycystin 1 and 2 have been demonstrated in vascular smooth muscle cells in the sarcoplasmic membrane suggesting a central role in regulating intracellular $\mathrm{Ca}^{2+}$ levels (20). In pkd2+/- mice vascular smooth muscle cells show altered intracellular $\mathrm{Ca}^{2+}$ homeostasis with reduced total intracellular and sarcoplasmic reticulum $\mathrm{Ca}^{2+}$ levels (21). Polycystin 2, which is normally conserved in drosophila, when reduced or when haploinsufficiency is present results in altered smooth muscle contractility (22). Importantly, recent investigations have demonstrated that stretch activated channels which respond to significant changes in vascular tone, are regulated by polycystin $1: 2$ complexes in vascular smooth muscle cells (Sharief-Naomi et al, Cell, 139 (3), 587-596, 2009). Polycystin 1 and 2 co-localize to the cilia of mouse and human vascular endothelial cells (23). Normal polycystin 1 and 2 function are required for endothelial cilia to sense fluid shear stress through a complex biochemical cascade involving calcium, calmodulin Akt/PKG and protein kinase C $(15,23,24)$. Normal endothelial cells exposed to fluid shear stress over hours results in polycystin 1 undergoing proteolytic cleavage. Abnormal ciliary polycystin-2 function leads to compromised fluid sensing as well, which impairs synthesis of NO, a mediator for other downstream signaling pathways involved in vascular smooth muscle relaxation. In response to fluid shear stress, mouse Pkd2-I- endothelial cells lose the ability to generate NO. Therefore, it appears that polycystin 1 and 2 may have a specific shear-sensing role in endothelial cilia.

\section{Systemic and Cardiovascular Characteristics of ADPKD ADPKD Children}

Data from large ADPKD registries indicate that blood pressures are elevated on average by 4$6 \mathrm{~mm} \mathrm{Hg}$ in children as compared to unaffected age- and gender-matched controls. Ten to $20 \%$ demonstrate hypertension or blood pressures greater than the $95^{\text {th }}$ percentile reported for age and gender when measured in the medical office $(25,26)$. Ambulatory blood pressure monitoring (ABPM) shows an increased rate of detection of hypertension compared to office blood pressure measurements (34\% vs. 16\%) (26). Specifically, ADPKD boys demonstrate a reduced day: night systolic and diastolic blood pressure ratios vs. unaffected age-matched controls (26) with more than $25 \%$ demonstrating a lack of normal nocturnal decline in blood pressure. Whether home blood pressure monitoring is as effective in detecting hypertension in ADPKD children as ABPM has not yet been determined.

Elevations in systolic and diastolic blood pressure and left ventricular mass index (LVMI) are found in affected vs. unaffected children $(25,27)$. Cardiac valve abnormalities occur with increased frequency in ADPKD children, specifically mitral valve prolapse and aortic insufficiency. ADPKD children demonstrate significantly greater LVMI in hypertensive subgroups that associate with systolic or diastolic blood pressure (28). ADPKD children with increased blood pressure or hypertension demonstrate greater kidney volume, cyst number and a greater rate of increase in kidney volume in comparison to age matched normotensive ADPKD children $(25,28)$. In addition, normotensive children demonstrate a significant 
correlation between kidney volume and systolic and diastolic blood pressures, to a greater extent than that observed in ADPKD adults (28). These observations have been confirmed using ABPM in 58 ADPKD children where kidney volume correlates with daytime systolic and nighttime systolic and diastolic blood pressures (29). Renal concentrating ability, which is decreased in approximately half of ADPKD children, is more often present in those who are hypertensive. Importantly, concentrating ability is inversely associated with ABPM systolic and diastolic pressures and the number of renal cysts (30). Decreased concentrating ability in ADPKD is associated with increased circulating vasopressin levels (31) potentially accounting for the elevations in blood pressure seen in ADPKD children. To date, evaluation of systemic vascular (ie: forearm vascular reactivity) or cardiac (ejection fraction, ventricular relaxation, pulse wave velocity or carotid wall thickness) function have not been evaluated in ADPKD children.

\section{Normotensive ADPKD Adults}

Normotensive ADPKD adults demonstrate increased left ventricular mass index (LVMI) vs. unaffected age and gender-matched controls (32) and LVMI correlates significantly throughout the range of systolic and diastolic blood pressure in normotensive ADPKD adults $(33,34)$. Echocardiography in normotensive ADPKD individuals demonstrates increased left and right ventricular mass and volumes with normal ejection fractions, and decreased end-diastolic relaxation. Importantly, coronary vascular reserve is diminished in normotensive ADPKD patients compared to healthy controls $(35,36)$. In addition, there is an exaggerated diastolic blood pressure response during exercise in normotensive ADPKD individuals suggesting an impaired capacity for exercise-induced vasodilatation (37). Multiple studies have demonstrated increased carotid intimal-medial thickness in normotensive ADPKD patients and is associated with increased levels of urinary albumin excretion $(35,36,38-40)$. Integrated back scatter of the carotid wall, an indirect measure of local tissue fibrosis, shows increased involvement of the carotid arteries in normotensive ADPKD patients vs. healthy controls (40).

Endothelial dependent relaxation is impaired in normotensive ADPKD individuals prior to loss of kidney function (41). Two relatively non-invasive methods that measure endothelial function: forearm brachial artery dilation in response to shear stress (42) and ex-vivo exposure of resistance vessels to increasing doses of acetylcholine (41) have been tested in patients with ADPKD. Both show a diminished capability of the endothelium to respond appropriately to vasodilatory stressors. Brachial artery dilatory capacity is reduced approximately $10-30 \%$ (39) and is associated with abnormal circadian blood pressure patterns in ADPKD (42). This abnormality is further exaggerated in hypertensive ADPKD patients (see below). Importantly, impaired brachial artery dilation in response to shear stress is not associated with albuminuria as has been demonstrated with increased LVMI in ADPKD (38). Acetylcholine-induced endothelial dependent relaxation is impaired in subcutaneous vessels from gluteal region in ADPKD patients (43). This impairment is not due to a decreased ability of vascular smooth muscle cells to respond to $\mathrm{NO}$ but rather defective $\mathrm{NO}$ generation from diminished $\mathrm{NO}$ synthase activity $(41,43)$.

\section{Hypertensive ADPKD Adults}

Hypertension is common in ADPKD and occurs prior to loss of kidney function in $>60 \%$ of affected individuals $(7,8,26,44)$ and occurs earlier and more commonly in PKD1 vs. PKD2 patients. Hypertension in an affected parent is associated with an increased frequency and earlier age of onset of hypertension in ADPKD offspring (45). The average age of onset of hypertension is between 30 and 34 years $(7,8,46,47)$ with men more commonly affected than women (1). The frequency of hypertension measured by ABPM or home blood pressure monitoring in ADPKD has not been determined. However, reliability and accuracy of home blood pressure measurements in hypertensive ADPKD individuals has been demonstrated in 
multiple clinical trials $(48,49)$. Early onset of hypertension is associated with a poorer renal prognosis in ADPKD where those diagnosed prior to age 35 are more likely to progress to ESRD $(11,50)$. Although recognition of hypertension has improved in ADPKD, successful achievement of blood pressure goals of $<130 / 80 \mathrm{~mm} \mathrm{Hg}$ occur in less than $30 \%$ of patients.

ABPM in hypertensive ADPKD individuals demonstrates a decreased frequency of nocturnal dipping vs. normotensive ADPKD individuals $(51,52)$. Non-dippers (less than $10 \%$ decline in systolic or diastolic blood pressure) are present in up to $45 \%$ of hypertensive patients prior to loss of renal function $(37,48,52)$. Reproducibility of dipping status measured by ABPM in treated hypertensive ADPKD individuals over extended periods of time (up to 9 months) have been low at 33\% (52), however, short term ( 2 week) repeat measures demonstrate better reproducibility closer to $68 \%$ (48). Reproducible ABPM in ADPKD has the potential to provide more detailed evaluation of blood pressure load, particularly circadian patterns in ADPKD in response to therapeutic interventions.

Hypertensive ADPKD adults with normal kidney function demonstrate a greater frequency of left ventricular hypertrophy (LVH) vs. normotensive ADPKD men (50 vs. $30 \%$ ) and women (52 vs. $22 \%$ ) as well as healthy controls (33). Hypertensive ADPKD men ( $\mathrm{n}=20)$ also demonstrate greater LVMI in comparison to matched essential hypertensive men (53). LVMI and left ventricular hypertrophy increase in frequency as hypertensive patients progress to renal failure with up to $70 \%$ of ESRD patients demonstrating LVH $(54,55)$. Associations between level of systolic and diastolic blood pressure control, proteinuria, body mass index, age, level of kidney function, and measures of insulin resistance have been shown to independently associate with LVMI in ADPKD (33,56,57). Importantly, mitral valve prolapse is found with increasing frequency in ADPKD adults vs. the general population, with mitral regurgitation but not mitral valve prolapse associating with blood pressure level (56). Intimal-medial thickness of the carotid arteries is increased in hypertensive ADPKD patients with normal kidney function as compared to normotensive ADPKD individuals and gender matched essential hypertensive patients (39). As well, greater fibromatous areas in the carotid wall are found in hypertensive ADPKD patients (30.2\%) vs. matched essential hypertensive individuals $(22.5 \%)(40)$.

Association between severity of kidney disease and hypertension is a characteristic of ADPKD. Hypertensive ADPKD patients with normal kidney function demonstrate greater kidney volumes vs. age matched normotensive ADPKD men and women $(7,8)$, a greater rate of increase in kidney volume $(7,58)$, increased proteinuria $(59,60)$ and decreased renal blood flow (61). Renal blood flow is reduced in hypertensive ADPKD patients vs. matched essential hypertensive patients (61) and renal resistive indices are increased in hypertensive ADPKD individuals and associate with loss of kidney function (62). Importantly, in hypertensive ADPKD individuals, renal blood flow decline parallels kidney volume increase, precedes loss of glomerular filtration rate and predicts structural and functional kidney disease progression (63) suggesting that reduced renal blood flow is a characteristic of hypertension in ADPKD.

\section{Hemodynamic Characteristics and Mechanisms Responsible for the Development of Hypertension in ADPKD}

Data indicate that as renal cysts enlarge, they compress the renal vasculature causing intrarenal ischemia, attenuation of the renal vasculature, and intra-renal activation of the reninangiotensin aldosterone system $(61,64-68)$. Biopsy data from both nephrectomy and autopsy specimens show increased concentrations of renin in the juxta-glomerular apparatus, arterioles, small arteries, connective tissue cells around the cysts and in attenuated vessels within the cyst wall $(64,69)$. 
Clinical studies show higher plasma renin activity and aldosterone concentrations in supine and upright positions and in response to angiotensin converting enzyme (ACE) inhibitors in ADPKD compared to matched patients with essential hypertension (61). Some $(61,65)$, but not all (32) have found higher plasma renin and aldosterone levels and a more pronounced decrease in renal vascular resistance after administration of angiotensin converting enzyme inhibition in ADPKD compared to patients with essential hypertension. These data suggest that inhibition of the RAAS may be important in attenuating the hypertension in this disease, reducing the rate of cyst growth and renal enlargement, ultimately slowing the progression to renal failure.

Renal tissue nitric oxide synthase activity is significantly reduced in ADPKD individuals with and without chronic kidney disease and plasma and urinary nitrate activities are decreased in hypertensive and normotensive ADPKD individuals with and without chronic kidney disease $(41,70)$. Endothelial NOS activity is also abnormal in ADPKD, which may result in activation of local oxidative stress pathways. Increased local oxidative stress due to reduced endothelial and vascular smooth muscle polycystin expression levels may also result in activation of the local renin-angiotensin aldosterone system. Angiotensin II has been established as an important growth factor in both kidney epithelial and interstitial fibroblasts, and the renin-angiotensinaldosterone system (RAAS) may play a role in cyst growth and expansion and kidney fibrosis in ADPKD independent of blood pressure. With increasing cyst size, activation of the RAAS occurs, blood pressure increases, and a vicious cycle ensues with enhanced cyst growth, hypertension, more cyst growth, ultimately leading to ESRD (Figure 1).

\section{Evidence for potential local inhibition of the renin-angiotensin aldosterone system in ADPKD}

Administration of ACE inhibitors or angiotensin receptor blocking agents individually fails to completely suppress systemic or local angiotensin II levels or action. Specifically in ADPKD kidneys, increased local chymase activity is present suggesting that non-ACE dependent mechanisms for activation of renal RAAS activation exist in ADPKD (71). To determine the feasibility of more complete inhibition of activity of the RAAS with combination of ACE inhibitors and angiotensin receptor blockers in low doses, 7 hypertensive ADPKD individuals with iothalamate clearances greater than $100 \mathrm{mls} / \mathrm{min}$ underwent a randomized four-way crossover/double-blind study involving 14 days of drug administration separated by 14 days washout with either placebo, enalapril $20 \mathrm{mg} / \mathrm{day}$, losartan $50 \mathrm{mg} / \mathrm{day}$, or enalapril $20 \mathrm{mg}$ and losartan $50 \mathrm{mg} /$ day combined (72,73). At the end of each treatment period, subjects were placed in sodium and potassium balance with three days of $100 \mathrm{mEq}$ sodium, $60 \mathrm{mEq}$ potassium and $1 \mathrm{gm} / \mathrm{kg} /$ day protein intake. After establishing sodium balance, subjects underwent infusion of either intravenous angiotensin $\mathrm{I}(1,4,8$, and $16 \mathrm{pmol} / \mathrm{kg} / \mathrm{min}$ for 10 minutes each) or angiotensin II ( 1 and $4 \mathrm{pmol} / \mathrm{kg} / \mathrm{min}$ for 20 minutes each). During infusion with angiotensin I and II, systemic blood pressure and plasma aldosterone concentrations increased in the presence of ACEI inhibitor, angiotensin receptor antagonist monotherapy or placebo (Figure $2 \mathrm{a}$ and $\mathrm{b}, 3 \mathrm{a}$ and $\mathrm{b}$ ). In contrast, neither systemic blood pressure nor plasma aldosterone concentrations changed from baseline during angiotensin I and II infusions when patients were receiving both enalapril and losartan therapy (Figure 2a and b, 3a and b). Peak systolic blood pressures and plasma aldosterone concentrations were significantly different in the combination therapy group vs. all others $(\mathrm{P}<0.001)$. Therefore given that angiotensin II plays a central role in the hypertension of ADPKD, combination therapy with angiotensin converting enzyme inhibitors and angiotensin receptor antagonists may be superior in providing more complete blockade of the RAAS. Whether combination therapy is necessary to treat hypertension and slow progression of renal disease in ADPKD awaits further study. 


\section{Intervention in Hypertension in ADPKD: Are There Benefits?}

Retrospective reports have demonstrated an association between the utilization of ACE inhibitor therapy as a first line agent for the treatment of hypertension in ADPKD and an extension of the average age of initiation of dialysis by over 10 years (67). However results of multiple randomized controlled trials addressing the impact of inhibition of RAAS in ADPKD subjects have not demonstrated significant benefit (49,74-76). In a prospective, randomized, double blind, placebo controlled study to assess the benefits of ACEI on kidney progression in non-diabetic kidney diseases including 64 ADPKD individuals with a mean creatinine clearance $42 \mathrm{~mL} / \mathrm{min}$ over 3 years, Maschio and colleagues demonstrated no benefit of ramipril with an equal frequency of doubling of serum creatinine concentration (27\%) as compared to the placebo controlled group (26\%) (74). The Modified Diet in Renal Disease (MDRD) study utilized a 2-by-2 factorial design to compare two levels of dietary protein/phosphorous intake and two levels of blood pressure control in patients with GFRs between 13 and $55 \mathrm{mls} / \mathrm{min} /$ $1.73 \mathrm{~m}^{2}$ included 200 ADPKD individuals. No benefits of low blood pressure control (MAP) $</=92 \mathrm{~mm} \mathrm{Hg}$ for age $</=60$ and $</=98 \mathrm{~mm} \mathrm{Hg}$ for age $>60$ ) were seen and over $40 \%$ received ACEI (75).. Although ACEI therapy was not randomized, no benefits of ACEI were seen on rate of GFR decline.

In a 7 year prospective trial of 72 ADPKD individuals with creatinine clearances $>30 \mathrm{mls} / \mathrm{min}$ assessing both level of blood pressure control and use of the ACEI enalapril vs. the calcium channel blocker amlodipine, no benefit was found with regard to preservation of renal function. However, relative reduction in urinary protein excretion and left ventricular mass index were seen with ACEI therapy in this study (49). Similarly, findings in a small randomized controlled trial of 24 early stage ADPKD patients treated chronically with either ACEI or calcium channel blocker over 5 years showed significant reduction in proteinuria, but no difference in serum measures of kidney function (76). Finally, a meta-analysis of 142 ADPKD subjects from 8 trials in non-diabetic kidney disease reported a $25 \%$ non-significant relative risk reduction in the composite endpoint of ESRD or doubling of serum creatinine in individuals on ACEI compared with other antihypertensive agents(77). Taken together, past studies have been limited by small numbers of patients at relatively late stages of disease.

The HALT PKD trials are two prospective randomized double blind placebo-controlled multicenter interventional trials utilizing the same stepwise intervention. The trials will test whether multi-level blockade of the RAAS using ACEi+ARB (lisinopril + telmisartan) combination therapy will delay progression of renal disease vs. ACEi (lisinopril + placebo) monotherapy in Study A and B and whether lower goal blood pressure control will delay progression as compared with standard control in Study A. Standard BP control for this study is defined as 120-130/70-80 and low BP as 95-110/60-75 (47). Unique features of these trials include the use of home blood pressure measurements for drug titration and treatment goals, and the primary endpoint of change in kidney volume measured by MR in the study group of early ADPKD patients (Study A). The design of HALT-PKD Study A and Study B addresses several issues required for the conduct of large multicenter trials including the selection of an appropriate drug intervention, selection of an appropriate stage of kidney disease where an intervention may be most effective, and selection of readily defined study endpoints. Enrollment in this study is now complete with 1170 participants randomized. Importantly, blood pressure targets have been reached in study groups relatively easily, with only a minority needing $2^{\text {nd }}$ and $3^{\text {rd }}$ line antihypertensive medications in addition to study medications (78, 79). The results of these trials will guide clinicians with regard to selection of antihypertensive agents targeting the slowing of progression of renal disease in ADPKD.

Current approaches to the treatment of hypertension in ADPKD should include 1) early recognition of elevations in blood pressure, preferably through home blood pressure monitoring, 2) aggressive control of blood pressure to $<130 / 80 \mathrm{mmHg}$ and 3) consideration 
of first line use of inhibitors of the RAAS with either angiotensin converting enzyme inhibitors or angiotensin receptor blocking agents. Optimization of blood pressure in ADPKD patients can also be achieved through appropriate lifestyle modifications including daily exercise, weight reduction, smoking cessation and reductions in sodium intake. Regular monitoring of patients with home blood pressure monitoring, dietary, exercise and lifestyle review all can contribute to optimal blood pressure control.

\section{Conclusions}

Hypertension of ADPKD occurs early and frequently in ADPKD and contributes significantly to patient morbidity and mortality, associating with progression to ESRD. Exciting recent discoveries of the potential role for the polycystins in regulating vascular tone through alterations in both endothelial and vascular smooth muscle cell function suggests that increases in systemic blood pressure may be a primary feature in ADPKD. Activation of the RAAS through abnormal endothelial-NO, cardiac function and renal cystic expansion plays a central role in the hypertension found in ADPKD. Whether maximal inhibition of the RAAS utilizing both ACEI and angiotensin receptor blocking agents is yet to be determined. Current randomized clinical trials including the HALT PKD clinical trials, due to be completed in 2013, are underway to determine if level of blood pressure control or maximal inhibition of the RAAS can slow progression of renal disease in ADPKD.

\section{Acknowledgments}

Sources of Support:

This work is supported by the PKD Foundation, NIDDK cooperative agreements U01 DK56956 (CRISP) and U01 DK62408 (HALT-PKD), NCRR CTSA UL1 RR025008, and NIDDK Nephrology Institutional Training grant T32 DK007656.

\section{References}

1. Gabow PA. Autosomal dominant polycystic kidney disease. N Engl J Med 1993;329:332-342. [PubMed: 8321262]

2. Torres VE, Harris PC. Autosomal dominant polycystic kidney disease: the last 3 years. Kidney Int 2009;76:149-168. [PubMed: 19455193]

3. Chapman AB. Approaches to testing new treatments in autosomal dominant polycystic kidney disease: insights from the CRISP and HALT-PKD studies. Clin J Am Soc Nephrol 2008;3:1197-1204. [PubMed: 18579674]

4. Perrone RD, Ruthazer R, Terrin NC. Survival after end-stage renal disease in autosomal dominant polycystic kidney disease: contribution of extrarenal complications to mortality. Am J Kidney Dis 2001;38:777-784. [PubMed: 11576881]

5. Rahman E, Niaz FA, Al-Suwaida A, et al. Analysis of causes of mortality in patients with autosomal dominant polycystic kidney disease: a single center study. Saudi J Kidney Dis Transpl 2009;20:806810. [PubMed: 19736478]

6. Chang MY, Kuok CM, Chen YC, et al. Comparison of Intracerebral Hemorrhage and Subarachnoid Hemorrhage in Patients with Autosomal-Dominant Polycystic Kidney Disease. Nephron Clin Pract 2009;114:c158-c164. [PubMed: 19907190]

7. Chapman AB, Guay-Woodford LM, Grantham JJ, et al. Renal structure in early autosomal-dominant polycystic kidney disease (ADPKD): The Consortium for Radiologic Imaging Studies of Polycystic Kidney Disease (CRISP) cohort. Kidney Int 2003;64:1035-1045. [PubMed: 12911554]

8. Chapman AB, Gabow PA. Hypertension in autosomal dominant polycystic kidney disease. Kidney Int Suppl 1997;61:S71-73. [PubMed: 9328971]

9. Schrier RW. Renal volume, renin-angiotensin-aldosterone system, hypertension, and left ventricular hypertrophy in patients with autosomal dominant polycystic kidney disease. J Am Soc Nephrol 2009;20:1888-1893. [PubMed: 19696226] 
10. Iglesias CG, Torres VE, Offord KP, Holley KE, Beard CM, Kurland LT. Epidemiology of adult polycystic kidney disease, Olmsted County, Minnesota: 1935-1980. Am J Kidney Dis 1983;2:630639. [PubMed: 6846334]

11. Gabow PA, Johnson AM, Kaehny WD, et al. Factors affecting the progression of renal disease in autosomal-dominant polycystic kidney disease. Kidney Int 1992;41:1311-1319. [PubMed: 1614046]

12. Boulter C, Mulroy S, Webb S, Fleming S, Brindle K, Sandford R. Cardiovascular, skeletal, and renal defects in mice with a targeted disruption of the Pkd1 gene. Proc Natl Acad Sci U S A 2001;98:1217412179. [PubMed: 11593033]

13. Wu G, Markowitz GS, Li L, et al. Cardiac defects and renal failure in mice with targeted mutations in Pkd2. Nat Genet 2000;24:75-78. [PubMed: 10615132]

14. McGrath J, Somlo S, Makova S, Tian X, Brueckner M. Two populations of node monocilia initiate left-right asymmetry in the mouse. Cell 2003;114:61-73. [PubMed: 12859898]

15. Kim K, Drummond I, Ibraghimov-Beskrovnaya O, Klinger K, Arnaout MA. Polycystin 1 is required for the structural integrity of blood vessels. Proc Natl Acad Sci U S A 2000;97:1731-1736. [PubMed: 10677526]

16. Lantinga-van Leeuwen IS, Dauwerse JG, Baelde HJ, et al. Lowering of Pkd1 expression is sufficient to cause polycystic kidney disease. Hum Mol Genet 2004;13:3069-3077. [PubMed: 15496422]

17. Lu W, Peissel B, Babakhanlou H, et al. Perinatal lethality with kidney and pancreas defects in mice with a targetted Pkd1 mutation. Nat Genet 1997;17:179-181. [PubMed: 9326937]

18. Pennekamp P, Karcher C, Fischer A, Schwickert A, Skryabin B, Horst J, Blum M, Dworniczak B. The ion channel polycystin-2 is required for left right axis determination in mice. Curr Biol 2002;412 (11):938-43. [PubMed: 12062060]

19. Hassane S, Claij N, Lantinga-van Leeuwen IS, et al. Pathogenic sequence for dissecting aneurysm formation in a hypomorphic polycystic kidney disease 1 mouse model. Arterioscler Thromb Vasc Biol 2007;27:2177-2183. [PubMed: 17656674]

20. Qian Q, Li M, Cai Y, et al. Analysis of the polycystins in aortic vascular smooth muscle cells. J Am Soc Nephrol 2003;14:2280-2287. [PubMed: 12937304]

21. Qian Q, Hunter LW, Li M, et al. Pkd2 haploinsufficiency alters intracellular calcium regulation in vascular smooth muscle cells. Hum Mol Genet 2003;12:1875-1880. [PubMed: 12874107]

22. Gao Z, Joseph E, Ruden DM, Lu X. Drosophila Pkd2 is haploid-insufficient for mediating optimal smooth muscle contractility. J Biol Chem 2004;279:14225-14231. [PubMed: 14732716]

23. Nauli SM, Kawanabe Y, Kaminski JJ, Pearce WJ, Ingber DE, Zhou J. Endothelial cilia are fluid shear sensors that regulate calcium signaling and nitric oxide production through polycystin-1. Circulation 2008;117:1161-1171. [PubMed: 18285569]

24. Abou Alaiwi WA, Takahashi M, Mell BR, et al. Ciliary polycystin-2 is a mechanosensitive calcium channel involved in nitric oxide signaling cascades. Circ Res 2009;104:860-869. [PubMed: 19265036]

25. Fick-Brosnahan GM, Tran ZV, Johnson AM, Strain JD, Gabow PA. Progression of autosomaldominant polycystic kidney disease in children. Kidney Int 2001;59:1654-1662. [PubMed: 11318935]

26. Rizk D, Jurkovitz C, Veledar E, et al. Quality of life in autosomal dominant polycystic kidney disease patients not yet on dialysis. Clin J Am Soc Nephrol 2009;4:560-566. [PubMed: 19261830]

27. Ivy DD, Shaffer EM, Johnson AM, Kimberling WJ, Dobin A, Gabow PA. Cardiovascular abnormalities in children with autosomal dominant polycystic kidney disease. J Am Soc Nephrol 1995;5:2032-2036. [PubMed: 7579051]

28. Cadnapaphornchai MA, McFann K, Strain JD, Masoumi A, Schrier RW. Increased left ventricular mass in children with autosomal dominant polycystic kidney disease and borderline hypertension. Kidney Int 2008;74:1192-1196. [PubMed: 18716604]

29. Seeman T, Dusek J, Vondrichova H, et al. Ambulatory blood pressure correlates with renal volume and number of renal cysts in children with autosomal dominant polycystic kidney disease. Blood Press Monit 2003;8:107-110. [PubMed: 12900587]

30. Seeman T, Dusek J, Vondrak K, et al. Renal concentrating capacity is linked to blood pressure in children with autosomal dominant polycystic kidney disease. Physiol Res 2004;53:629-634.

[PubMed: 15588131] 
31. Torres VE. Role of vasopressin antagonists. Clin J Am Soc Nephrol 2008;3:1212-1218. [PubMed: 18434616]

32. Doulton TW, Saggar-Malik AK, He FJ, et al. The effect of sodium and angiotensin-converting enzyme inhibition on the classic circulating renin-angiotensin system in autosomal-dominant polycystic kidney disease patients. J Hypertens 2006;24:939-945. [PubMed: 16612257]

33. Chapman AB, Johnson AM, Rainguet S, Hossack K, Gabow P, Schrier RW. Left ventricular hypertrophy in autosomal dominant polycystic kidney disease. J Am Soc Nephrol 1997;8:1292-1297. [PubMed: 9259356]

34. Valero FA, Martinez-Vea A, Bardaji A, et al. Ambulatory blood pressure and left ventricular mass in normotensive patients with autosomal dominant polycystic kidney disease. J Am Soc Nephrol 1999;10:1020-1026. [PubMed: 10232688]

35. Turkmen K, Oflaz H, Uslu B, et al. Coronary flow velocity reserve and carotid intima media thickness in patients with autosomal dominant polycystic kidney disease: from impaired tubules to impaired carotid and coronary arteries. Clin J Am Soc Nephrol 2008;3:986-991. [PubMed: 18354076]

36. Ecder T, Schrier RW. Cardiovascular abnormalities in autosomal-dominant polycystic kidney disease. Nat Rev Nephrol 2009;5:221-228. [PubMed: 19322187]

37. Martinez-Vea A, Bardaj A, Gutierrez C, et al. Exercise blood pressure, cardiac structure, and diastolic function in young normotensive patients with polycystic kidney disease: a prehypertensive state. Am J Kidney Dis 2004;44:216-223. [PubMed: 15264179]

38. Azurmendi PJ, Fraga AR, Galan FM, et al. Early renal and vascular changes in ADPKD patients with low-grade albumin excretion and normal renal function. Nephrol Dial Transplant 2009;24:24582463. [PubMed: 19332866]

39. Kocaman O, Oflaz H, Yekeler E, et al. Endothelial dysfunction and increased carotid intima-media thickness in patients with autosomal dominant polycystic kidney disease. Am J Kidney Dis 2004;43:854-860. [PubMed: 15112176]

40. Rong S, Jin X, Ye C, Chen J, Mei C. Carotid vascular remodelling in patients with autosomal dominant polycystic kidney disease. Nephrology (Carlton) 2009;14:113-117. [PubMed: 19335845]

41. Wang D, Iversen J, Wilcox CS, Strandgaard S. Endothelial dysfunction and reduced nitric oxide in resistance arteries in autosomal-dominant polycystic kidney disease. Kidney Int 2003;64:1381-1388. [PubMed: 12969157]

42. Turgut F, Oflaz H, Namli S, et al. Ambulatory blood pressure and endothelial dysfunction in patients with autosomal dominant polycystic kidney disease. Ren Fail 2007;29:979-984. [PubMed: 18067044]

43. Wang D, Iversen J, Strandgaard S. Endothelium-dependent relaxation of small resistance vessels is impaired in patients with autosomal dominant polycystic kidney disease. J Am Soc Nephrol 2000;11:1371-1376. [PubMed: 10906150]

44. Serra AL, Kistler AD, Poster D, et al. Clinical proof-of-concept trial to assess the therapeutic effect of sirolimus in patients with autosomal dominant polycystic kidney disease: SUISSE ADPKD study. BMC Nephrol 2007;8:13. [PubMed: 17868472]

45. Schrier RW, Johnson AM, McFann K, Chapman AB. The role of parental hypertension in the frequency and age of diagnosis of hypertension in offspring with autosomal-dominant polycystic kidney disease. Kidney Int 2003;64:1792-1799. [PubMed: 14531813]

46. Parfrey PS, Barrett BJ. Hypertension in autosomal dominant polycystic kidney disease. Curr Opin Nephrol Hypertens 1995;4:460-464. [PubMed: 8564453]

47. Chapman AB, Torres VE, Perrone RD, et al. The HALT Polycystic Kidney Disease Trials - Design and Implementation. Clin J Am Soc Nephrol.

48. Rahbari-Oskoui F, Miskulin DC, Fielder O, et al. Reproducibility of ambulatory blood pressure monitoring (ABPM) in hypertensive (HBP) Autosomal Dominant Polycystic Kidney Disease (ADPKD). J Am Soc Nephrol 2008;19:122A.

49. Schrier R, McFann K, Johnson A, et al. Cardiac and renal effects of standard versus rigorous blood pressure control in autosomal-dominant polycystic kidney disease: results of a seven-year prospective randomized study. J Am Soc Nephrol 2002;13:1733-1739. [PubMed: 12089368] 
50. Idrizi A, Barbullushi M, Strakosha A, et al. The relation of hypertension, renal function and cardiovascular events in autosomal dominant polycystic kidney disease. G Ital Nefrol 2007;24:595599. [PubMed: 18278763]

51. Ramunni A, Brescia P, Quaranta D, et al. Cutaneous microcirculation is impaired in early autosomal dominant polycystic kidney disease. Nephron Clin Pract 2009;113:c71-75. [PubMed: 19602901]

52. Covic A, Mititiuc I, Gusbeth-Tatomir P, Goldsmith DJ. The reproducibility of the circadian BP rhythm in treated hypertensive patients with polycystic kidney disease and mild chronic renal impairment-a prospective ABPM study. J Nephrol 2002;15:497-506. [PubMed: 12455715]

53. Martinez-Vea A, Valero FA, Bardaji A, et al. Left ventricular hypertrophy in hypertensive patients with autosomal dominant polycystic kidney disease: influence of blood pressure and humoral and neurohormonal factors. Am J Nephrol 2000;20:193-200. [PubMed: 10878400]

54. Bardaji A, Martinez-Vea A, Valero A, et al. Cardiac involvement in autosomal-dominant polycystic kidney disease: a hypertensive heart disease. Clin Nephrol 2001;56:211-220. [PubMed: 11597036]

55. Levin A, Singer J, Thompson CR, Ross H, Lewis M. Prevalent left ventricular hypertrophy in the predialysis population: identifying opportunities for intervention. Am J Kidney Dis 1996;27:347354. [PubMed: 8604703]

56. Lumiaho A, Ikaheimo R, Miettinen R, et al. Mitral valve prolapse and mitral regurgitation are common in patients with polycystic kidney disease type 1. Am J Kidney Dis 2001;38:1208-1216. [PubMed: 11728952]

57. Lumiaho A, Pihlajamaki J, Hartikainen J, et al. Insulin resistance is related to left ventricular hypertrophy in patients with polycystic kidney disease type 1. Am J Kidney Dis 2003;41:1219-1224. [PubMed: 12776274]

58. Fick-Brosnahan GM, Belz MM, McFann KK, Johnson AM, Schrier RW. Relationship between renal volume growth and renal function in autosomal dominant polycystic kidney disease: a longitudinal study. Am J Kidney Dis 2002;39:1127-1134. [PubMed: 12046022]

59. Chapman AB, Johnson AM, Gabow PA, Schrier RW. Overt proteinuria and microalbuminuria in autosomal dominant polycystic kidney disease. J Am Soc Nephrol 1994;5:1349-1354. [PubMed: 7894001]

60. Grantham JJ, Chapman AB, Torres VE. Volume progression in autosomal dominant polycystic kidney disease: the major factor determining clinical outcomes. Clin J Am Soc Nephrol 2006;1:148-157. [PubMed: 17699202]

61. Chapman AB, Johnson A, Gabow PA, Schrier RW. The renin-angiotensin-aldosterone system and autosomal dominant polycystic kidney disease. N Engl J Med 1990;323:1091-1096. [PubMed: 2215576]

62. Kondo A, Akakura K, Ito H. Assessment of renal function with color Doppler ultrasound in autosomal dominant polycystic kidney disease. Int J Urol 2001;8:95-98. [PubMed: 11260332]

63. Torres VE, King BF, Chapman AB, et al. Magnetic resonance measurements of renal blood flow and disease progression in autosomal dominant polycystic kidney disease. Clin J Am Soc Nephrol 2007;2:112-120. [PubMed: 17699395]

64. Graham PC, Lindop GB. The anatomy of the renin-secreting cell in adult polycystic kidney disease. Kidney Int 1988;33:1084-1090. [PubMed: 3043076]

65. Torres VE, Wilson DM, Burnett JC Jr, Johnson CM, Offord KP. Effect of inhibition of converting enzyme on renal hemodynamics and sodium management in polycystic kidney disease. Mayo Clin Proc 1991;66:1010-1017. [PubMed: 1921483]

66. Watson ML, Macnicol AM, Allan PL, Wright AF. Effects of angiotensin converting enzyme inhibition in adult polycystic kidney disease. Kidney Int 1992;41:206-210. [PubMed: 1317477]

67. Ecder T, Edelstein CL, Fick-Brosnahan GM, et al. Diuretics versus angiotensin-converting enzyme inhibitors in autosomal dominant polycystic kidney disease. Am J Nephrol 2001;21:98-103. [PubMed: 11359016]

68. Wang D, Strandgaard S. The pathogenesis of hypertension in autosomal dominant polycystic kidney disease. J Hypertens 1997;15:925-933. [PubMed: 9321739]

69. Torres VE, Donovan KA, Scicli G, et al. Synthesis of renin by tubulocystic epithelium in autosomaldominant polycystic kidney disease. Kidney Int 1992;42:364-373. [PubMed: 1405319] 
70. Wang D, Strandgaard S, Borresen ML, et al. Asymmetric dimethylarginine and lipid peroxidation products in early autosomal dominant polycystic kidney disease. Am J Kidney Dis 2008;51:184191. [PubMed: 18215696]

71. McPherson EA, Luo Z, Brown RA, et al. Chymase-like angiotensin II-generating activity in endstage human autosomal dominant polycystic kidney disease. J Am Soc Nephrol 2004;15:493-500. [PubMed: 14747398]

72. Stepniakowski KT, Gerron GG, Chapman AB. Dissociation between systemic, adrenal, and renal response to angiotensin converting enzyme inhibition (Enalapril (En) $20 \mathrm{mg} / \mathrm{day}$ ), angiotensin receptor blocker (Losartan (Los) $50 \mathrm{mg} /$ day) vs combination therapy (En/Los) in subjects with autosomal dominant polycystic kidney disease (PKD) during equimolar intravenous angiotensin I (Ang I) and angtiotensin II (Ang II) infusion. Journal of the American Society of Nephrology 2002;13:507a-508a.

73. Stepniakowski KT, Gerron GG, Chapman AB. Basal systemic, adrenal and renal responses to angiotensin converting enzyme inhibitor (Enalapril (En) $2020 \mathrm{mg}$ ), angiotensin receptor blocker (Losartan (Los) $50 \mathrm{mg}$ ) vs. combination therapy in autosomal dominant polycystic kidney disease (PKD). Journal of the American Society of Nephrology 2002;13:508a-508a.

74. Maschio G, Alberti D, Janin G, et al. Effect of the angiotensin-converting-enzyme inhibitor benazepril on the progression of chronic renal insufficiency. The Angiotensin-Converting-Enzyme Inhibition in Progressive Renal Insufficiency Study Group. N Engl J Med 1996;334:939-945. [PubMed: 8596594]

75. Klahr S, Breyer JA, Beck GJ, Dennis VW, Hartman JA, Roth D, Steinman TI<, Wang SR, Yamamoto ME. Dietary protein restriction, blood pressure control and the progression of polycystic kidney disease. Modification of Diet in Renal Disease Study Group. J Am Soc Nephrol 5(12):2037-47. [PubMed: 7579052]

76. Nutahara K, Higashihara E, Horie S, et al. Calcium channel blocker versus angiotensin II receptor blocker in autosomal dominant polycystic kidney disease. Nephron Clin Pract 2005;99:c18-23. [PubMed: 15637459]

77. Jafar T, Stark PC, Schmid CH, Standgaard S, Kamper A, Maschio G, Becker G, Perrone RD, Levey A. The effect of angiotensin-converting enzyme inhibitors on progression of polycystic kidney disease (PKD). Kidney Int 2005;6(1):265-71. [PubMed: 15610250]

78. Torres VE, Schrier RW, Chapman AB, et al. Achievement and Maintenance of Blood Pressure Targets in HALT-PKD. J Am Soc Nephrol 2009;20:497A.

79. Torres VE, Schrier RW, Chapman AB, et al. HALT-PKD Clinical Trials, Baseline Parameters. J Am Soc Nephrol 2009;20:499A. 


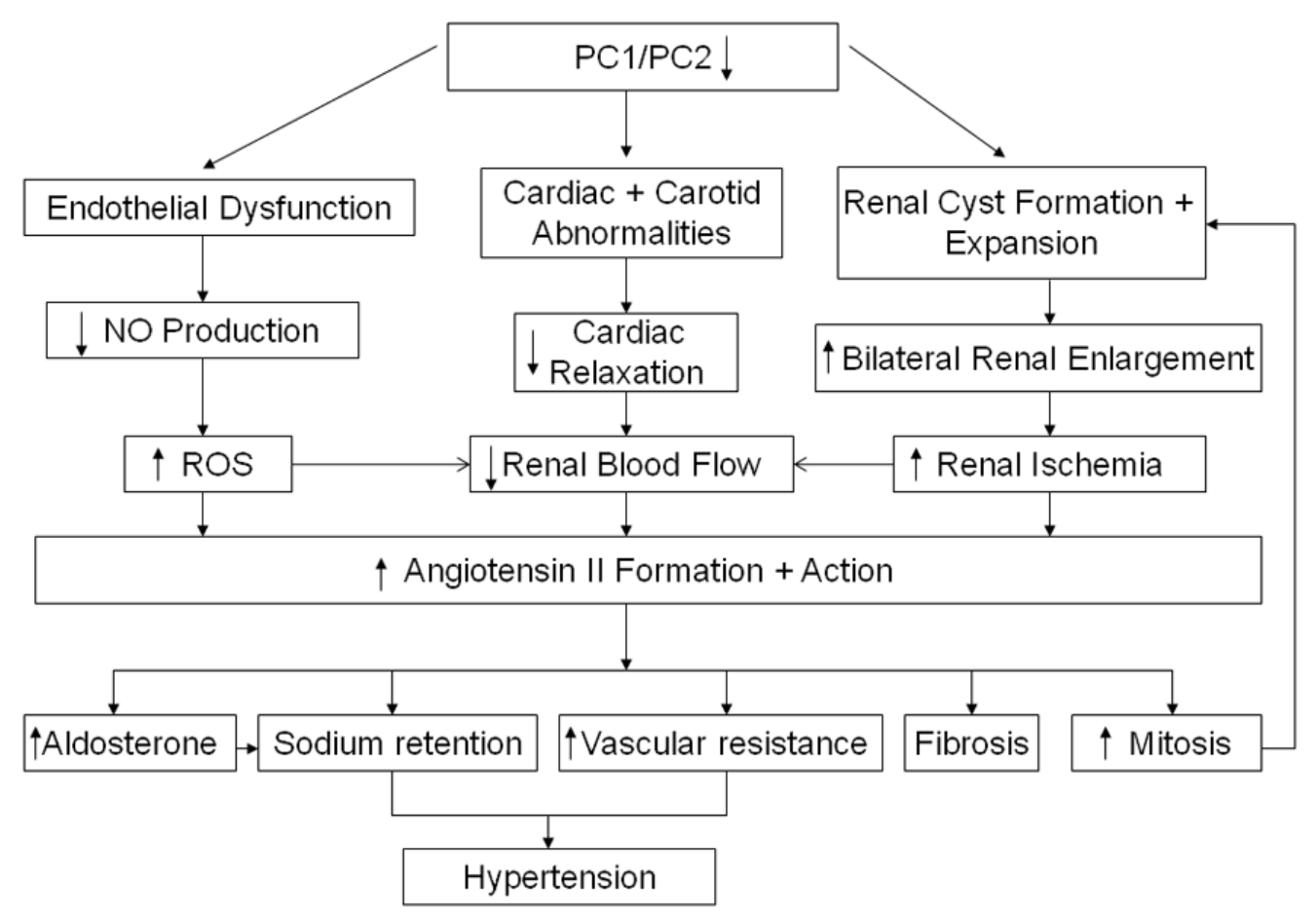

Figure 1.

Proposed model for pathogenesis of hypertension in ADPKD.

Reduction in polycystin 1 or 2 expression levels (PC1/PC2) result in endothelial, cardiac and carotid wall abnormalities in addition to renal cyst formation and expansion. Reduced nitric oxide (NO), cardiac relaxation and increased renal ischemia result in decreased renal blood flow and increased angiotensin II. Activation of the renin-angiotensin-aldosterone system results in increased blood pressure, tissue fibrosis and proliferation enhancing renal cyst growth. 


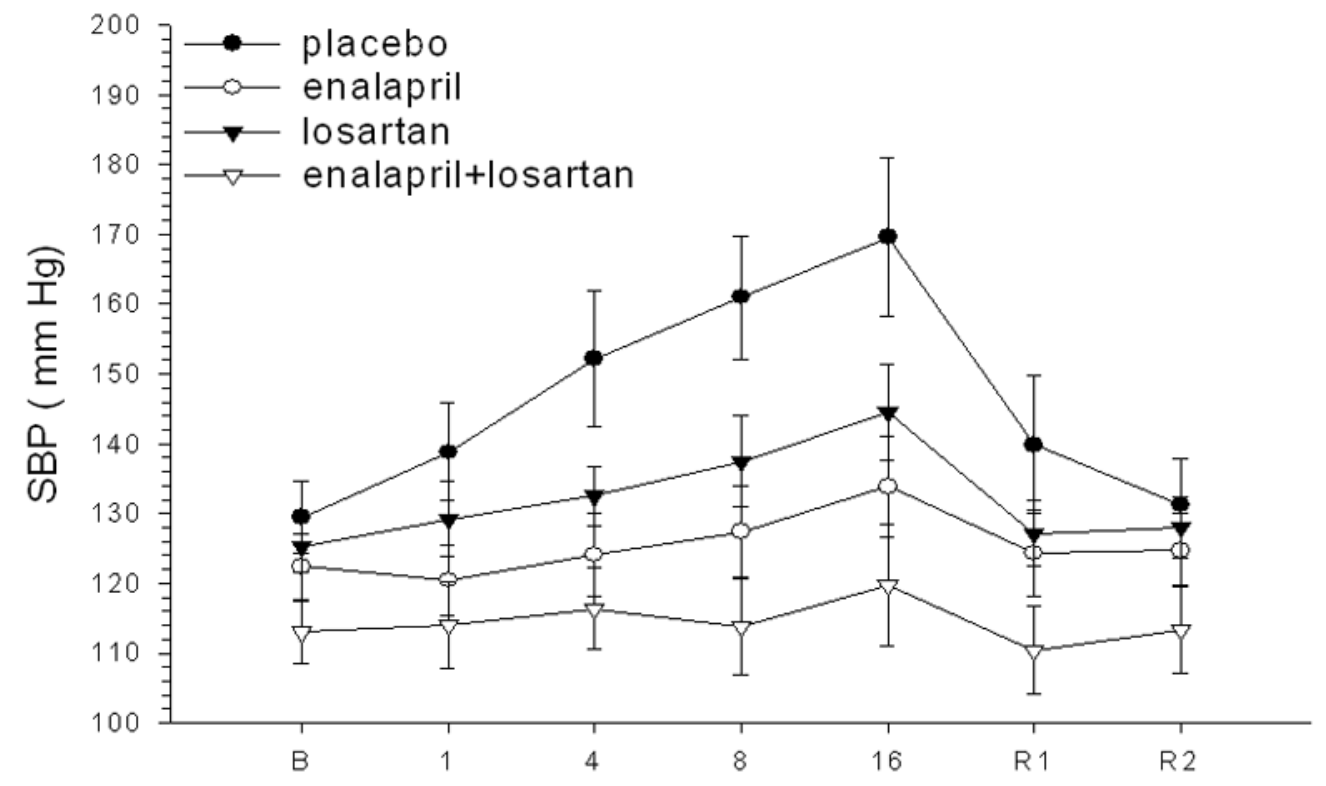

Angiotensin I ( $\mathrm{pmol} / \mathrm{kg} / \mathrm{min})$

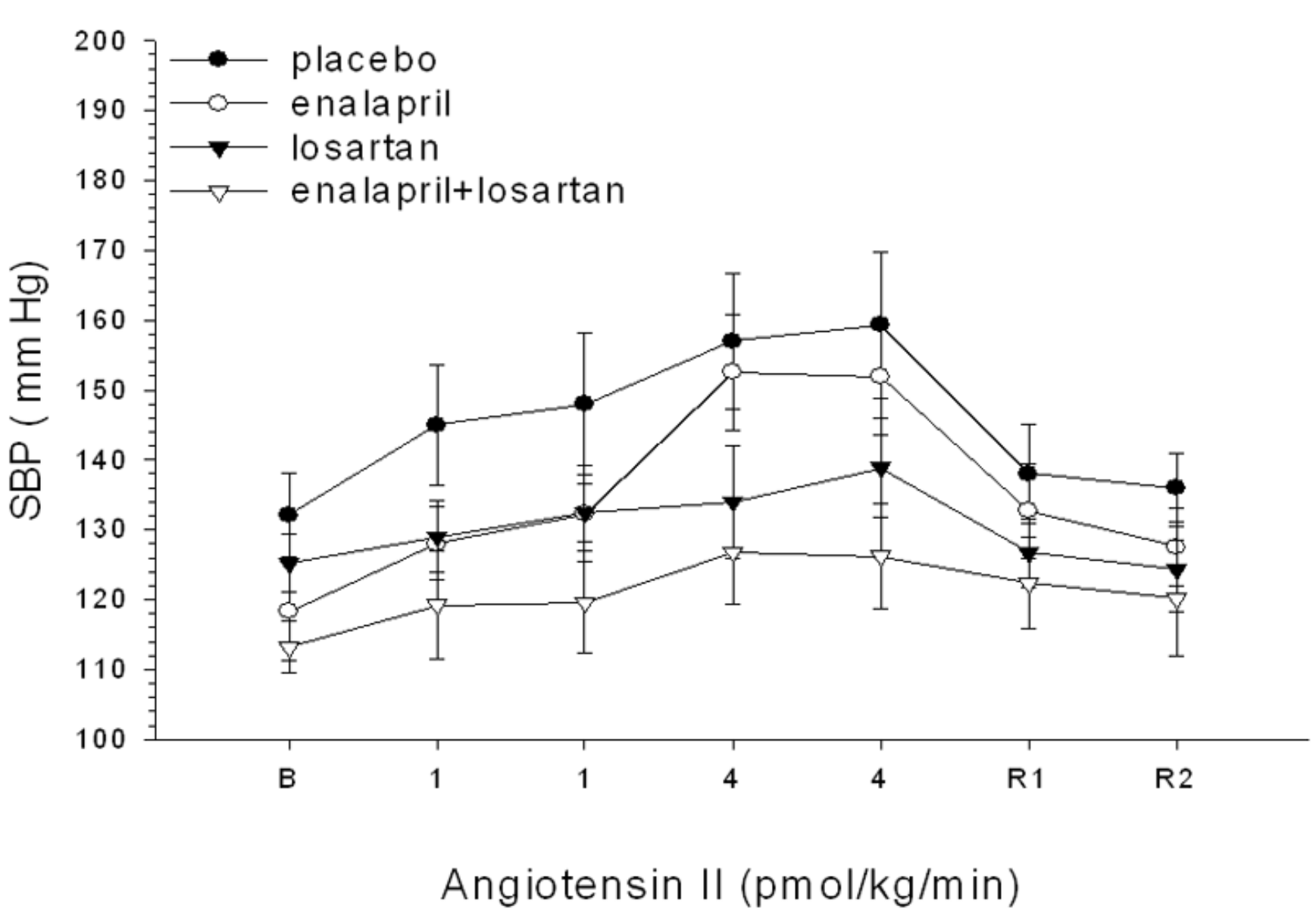

Figure 2. 
a,b. SBP response ( $\mathrm{mmHg}$ ) in 7 hypertensive ADPKD patients to intravenous angiotensin I and II infusions. SBP increased significantly from baseline periods in placebo, enalapril and losartan treatment periods. No change in SBP during angiotensin I and II infusions was seen in the combined losartan/enalapril period. Peak SBP were significantly greater in placebo, enalapril and losartan periods vs. the losartan/enalapril period $(\mathrm{p}<0.001)$. 


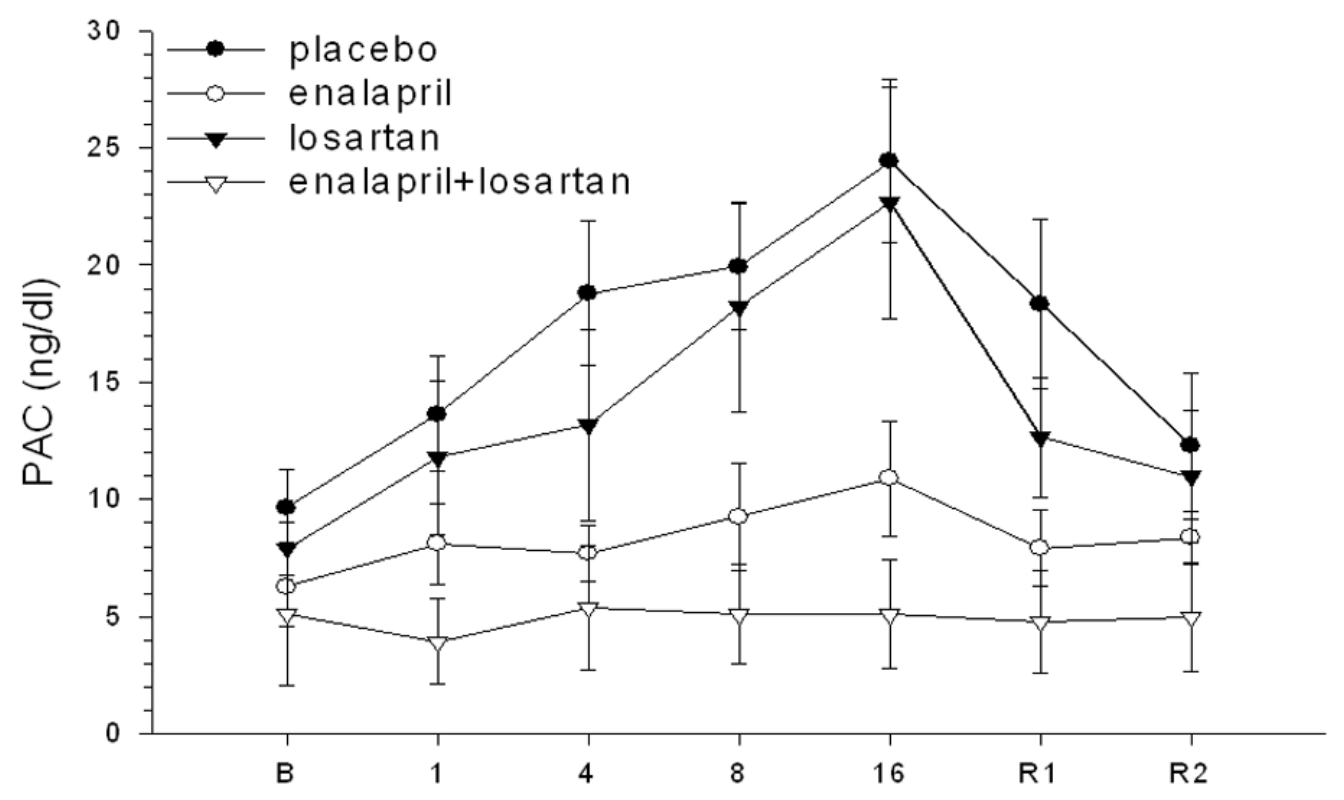

Angiotensin I (pmol/ $\mathrm{kg} / \mathrm{min})$

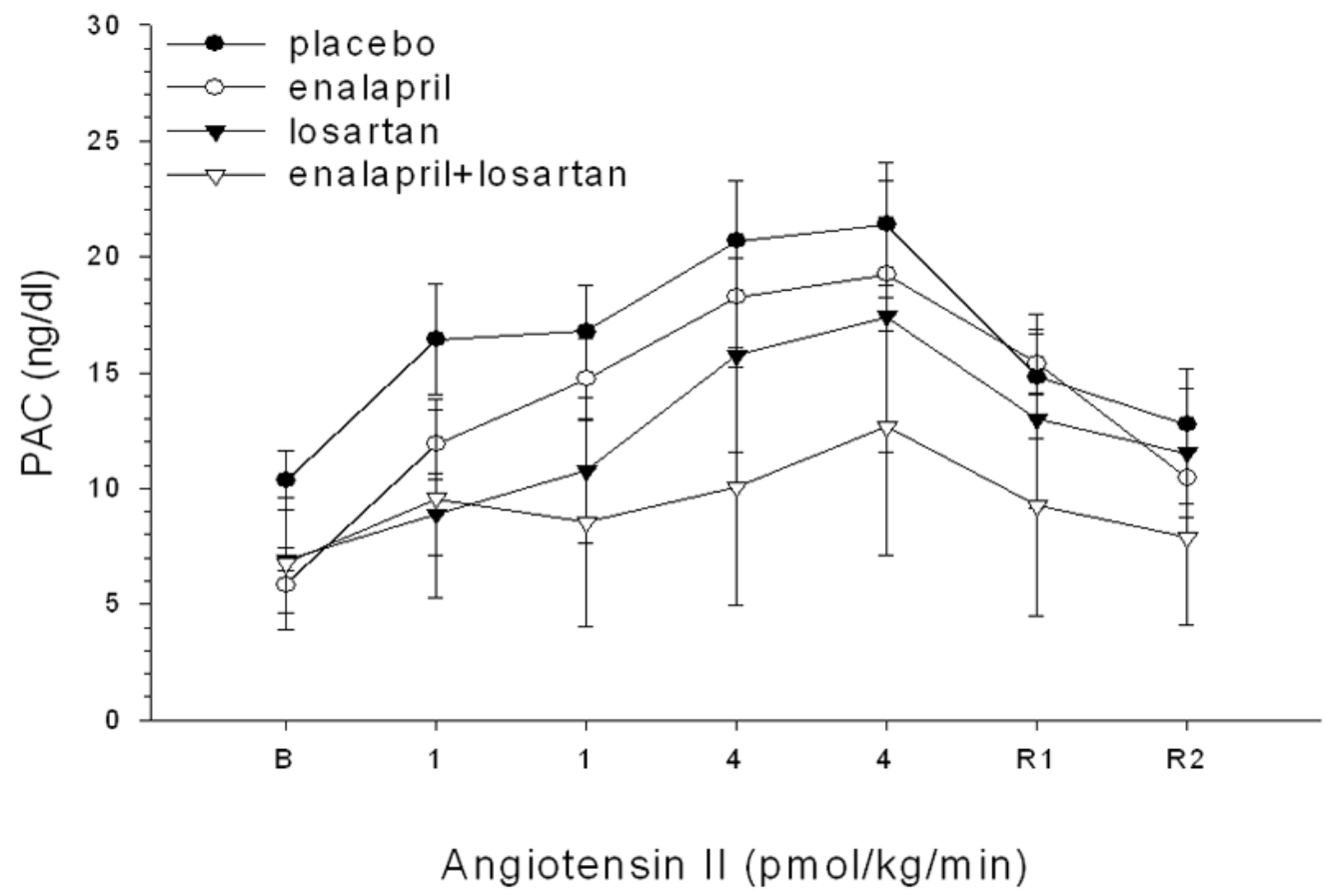

Figure 3.

a, b. Plasma aldosterone concentrations (PAC) (ng/dl) in 7 ADPKD hypertensive patients to intravenous angiotensin I and II infusions. PAC increased significantly from baseline in placebo, enalapril, and losartan treatment periods. No change in PAC was seen during angiotensin I and II infusions was seen in the combined losartan/enalapril period. Peak PAC was significantly greater in placebo, enalapril and losartan periods vs. the losartan/enalapril combined $(\mathrm{p}<0.001)$. 